\title{
Immunoexpression of CD95 in chronic gastritis and gastric mucosa-associated lymphomas
}

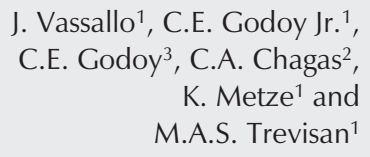

\author{
${ }^{1}$ Departamento de Anatomia Patológica and \\ ${ }^{2}$ Laboratório de Patologia Experimental, Faculdade de Ciências Médicas, \\ Universidade Estadual de Campinas, Campinas, SP, Brasil \\ ${ }^{3}$ Instituto de Patologia, São José dos Campos, SP, Brasil
}

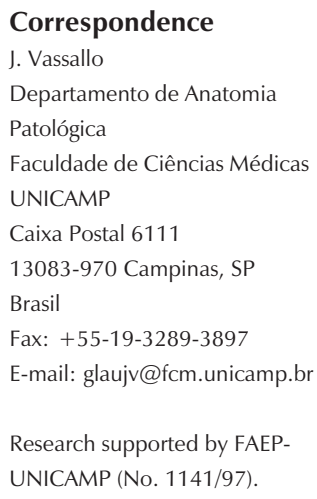

Publication supported by FAPESP. ......................

Received November 18, 2003 Accepted May 18, 2004

\begin{abstract}
CD95 (Fas/APO-1)-mediated apoptosis plays an important role in immunological regulation and is related to the pathogenesis of autoimmune diseases. Immunoexpression of CD95 has been reported to frequently occur in low grade non-Hodgkin lymphomas, especially of post-germinal center histogenesis, among which those originating in mucosa-associated lymphoid tissue (MALT lymphomas). However, there is no report comparing in situ immunoexpression of this marker in lymphomas and the hyperplastic lymphoid reaction (chronic gastritis) related to Helicobacter pylori infection. The purpose of the present research was to compare the intensity of lymphoid CD95 immunoexpression in 15 cases of $H$. pylori-related chronic gastritis and 15 gastric MALT lymphomas. CD95 (anti-CD95) was detected by an immunoperoxidase technique in paraffin sections using the catalyzed amplification system. Graduation of reaction intensity (percentage of CD95-positive cells) was semiquantitative, from 1+ to 4+. Nine cases of chronic gastritis were $4+$, five $2+$ and one $1+$. Three lymphomas were $4+$, three $3+$, four $2+$, four $1+$, and one was negative. Although 14 of 15 lymphomas were positive for CD95, the intensity of the reaction was significantly weaker compared to that obtained with gastric tissue for patients with gastritis $(P=0.03)$. The difference in CD95 immunoexpression does not seem to be useful as an isolated criterion in the differential diagnosis between chronic gastritis and MALT lymphomas since there was overlapping of immunostaining patterns. However, it suggests the possibility of a pathogenetic role of

this apoptosis-regulating protein in MALT lymphomas.
\end{abstract}

\section{Introduction}

The CD95 (Fas/APO1) antigen belongs to a family of transmembrane proteins, which includes the tumor necrosis factor receptor CD40 and the neural growth factor R, among others. CD95 is related to the induction of
Key words

- CD95

- FAS/APO1

- Apoptosis

- Chronic gastritis

- MALT lymphoma

..................... 
tion among both B- and T-cells after birth. These investigators also demonstrated that additional processes, besides Fas expression, might be present in order to induce apoptosis in lymphocytes exposed to antigens.

Lagresle et al. (2) have shown that simple expression of CD95 in germinal center Blymphoid cells did not correlate with increased sensitivity to apoptosis. Additional activation of these cells was necessary to induce cell death. These investigators postulated that CD95 might have a late regulatory function in B-cells in order to prevent proliferation of self-reactive, mutated or low-affinity clones. This regulation may involve, at least in part, down-regulation of genes favoring cell survival, such as $b c l-2$. Möller et al. (3) detected low levels of APO1 in a subset of lymphoid follicle center B-blasts and high levels in B-sinusoidal cells. APO1 was not detected in the follicle mantle zone or in plasma cells but was shown to be expressed in CD10-positive B-cells isolated from tonsils.

APO1 expression was also described in epithelial cells, especially in the basal layer. In contrast, satellite cells of autonomous nervous ganglia and all central nervous system cell types do not present APO1. An increased expression of APO1 in epithelial and mesothelial cells in contact with inflammatory infiltrate was observed and was attributed to the action of cytokines (4).

Little or no expression of APO1 has been reported in B-lymphoblastic and lymphocytic leukemias, Burkitt's lymphoma, hairy cell leukemia, and plasmocytoma. There was strong expression of APO1 in follicle center cell and mediastinal large B-cell lymphomas (3).

Nguyen et al. (5) investigated the immunoexpression of CD95 in malignant lymphomas and reported that $43 \%$ of the B-cell lymphomas were positive, especially those with low-grade histology (52\%). Among the latter, the lymphocytic (chronic lymphocytic leukemia) and the mantle cell lymphomas were generally negative, while mucosa-associated lymphoid tissue (MALT) and follicular lymphomas were frequently positive (92 and 64\%, respectively). Later studies have shown that sensitivity to apoptosis by the CD95 pathway might be altered, as none of the lymphomas studied by Plumas et al. (6), regardless of their level of CD95 expression, had apoptosis induced by the anti-CD95 monoclonal antibody. These investigators confirmed the low expression of CD95 in chronic lymphocytic leukemia and mantle cell lymphomas, and its high expression in follicular lymphomas.

In a flow cytometric quantitative study, Seeberger et al. (7) detected moderate expression of CD95 in normal memory Bcells, while MALT lymphoma cells presented low expression. In that study they also showed that addition of activated T-lymphocytes to the cell cultures increased CD95 expression in both cell types, but MALT lymphoma cells maintained lower levels of this protein. Further tests showed that both activated cell types presented low levels of cell death, but MALT lymphoma cells with higher levels of CD95 expression were more resistant to apoptosis. This indicates that resistance to CD95-mediated apoptosis (mutation or inactivation) may be involved in the genesis of lymphomas.

The pathogenesis of MALT lymphomas is intriguing since there is evidence that it may progress from inflammatory processes such as Helicobacter pylori-induced gastritis or autoimmune diseases (8). To the best of our knowledge, there are no studies comparing in situ protein expression of CD95 cells in $\mathrm{H}$. pylori-related gastritis and gastric MALT lymphomas. This information might be relevant to the understanding of the progression of inflammation to lymphoma, and as an aid for differential diagnosis when histological features are ambiguous. The purpose of the present study was to compare the immunoexpression of CD95 in histological sections diagnosed either as chronic gas- 
tritis (H. pylori positive) or gastric MALT lymphoma.

\section{Material and Methods}

Fifteen cases diagnosed as $H$. pylori-related intense chronic gastritis and 15 as gastric MALT lymphoma were selected from our files. Conventional histological sections stained with hematoxylin and eosin were reviewed and new sections from paraffin blocks were placed on sylanized slides for immunohistochemical study. After hydration and endogenous peroxidase blocking with $3 \% \mathrm{H}_{2} \mathrm{O}_{2}$, antigen retrieval was performed with a $10 \mathrm{mM}$ citrate buffer solution, $\mathrm{pH}$ 6.0, using a steamer (T-Fall ${ }^{\circledR}$, Dijon, France), at $90^{\circ} \mathrm{C}$, for $30 \mathrm{~min}$. Slides were incubated with an anti-CD95/APO1 antibody (Dakopatts, Carpinteria, CA, USA, code M3553) diluted at 1:10 in 1\% BSA-PBS, overnight $(18 \mathrm{~h})$ at $4^{\circ} \mathrm{C}$. Specific antibody binding was detected using the thyramidebased catalyzed amplification system (Dakopatts, code K1500). Slides were then stained with 3,3-diaminobenzidine, counterstained with hematoxylin, dehydrated and mounted with Entellan (Merck, Darmstadt, Germany, code 107961).

Immunostaining in lymphoid cells was graded using a 0 to $4+$ score, as follows: $0=$ no reactive cells present; $1+=$ up to $10 \%$ positive cells; $2+=>10$ to $40 \%$ positive cells; $3+=>40$ to $70 \%$ positive cells; $4+=$ $>70$ to $100 \%$ positive cells.

For comparison of immunostaining between groups the data were analyzed statistically by the Mann-Whitney test.

\section{Results and Discussion}

All 15 cases diagnosed as $H$. pylori-related gastritis presented some degree of CD95-positive lymphocytes: one was graded as $1+$, five as $2+$ and nine as $4+$ (Figure 1 ). In two cases in which immunostaining was very strong, superficial plasma cells also presented membrane reactivity.

Among the 15 cases diagnosed as MALT non-Hodgkin lymphomas, one did not present CD95-positive cells, four cases were graded as $1+$, four as $2+$, three as $3+$, and three as 4+ (Figure 2). In most cases of both

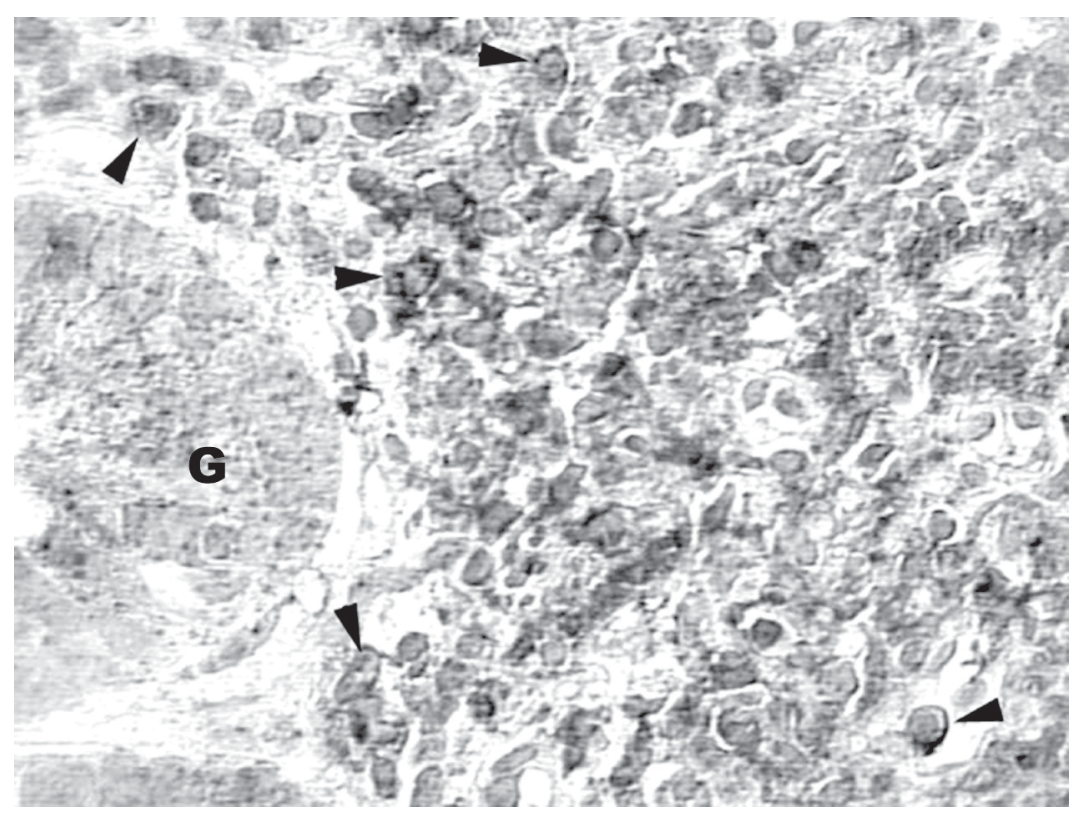

Figure 1. Chronic gastritis: most lymphocytes show membrane reaction with anti-CD95/ APO1 (arrowheads). Glandular cells (G) are negative (800X; bar $12.5 \mu \mathrm{m})$.

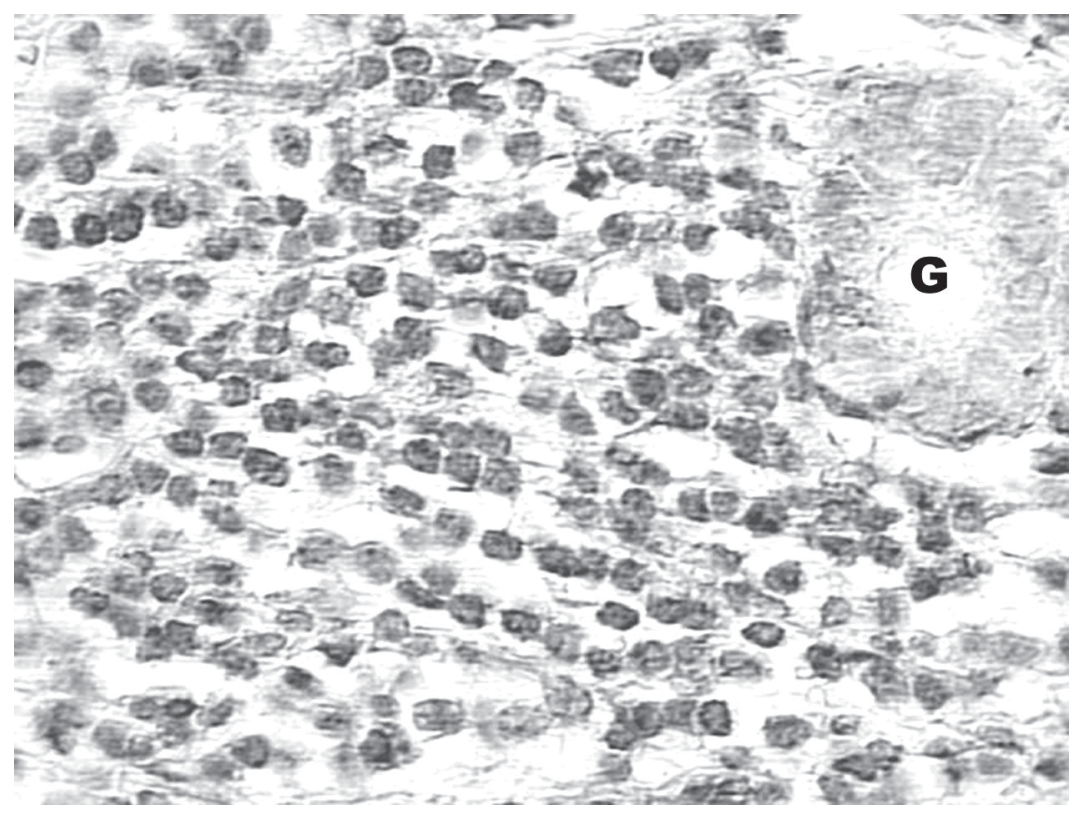

Figure 2. MALT Iymphoma: neoplastic lymphocytes and glandular epithelium (G) are negative for reaction with anti-CD95/APO1 (800X; bar $12.5 \mu \mathrm{m}$ ). 
groups foci of CD95-positive epithelial cells were also present at variable intensity.

Table 1 summarizes the number of cases and the respective scores for the chronic gastritis and MALT lymphoma groups. A statistically significant difference was detected between groups $(\mathrm{P}=0.03)$ in spite of overlapping degrees of CD95 immunoexpression.

In the present study we demonstrated that 14 of 15 MALT lymphomas (93\%) were positive for CD95. This finding is similar to the data reported by Nguyen et al. (5), in whose study 11 of 12 cases (92\%) were positive. In the latter study, however, neither the criteria used to consider a case as positive nor the pattern of reactivity were reported. Among our lymphomas, only 6 (40\%) presented reactivity of more than $40 \%$ of lymphoid cells (scores $3+$ and 4+), in contrast to the group with chronic gastritis. This finding supports the possibility that downregulation of CD95 expression might be involved in cell survival during the genesis of MALT lymphomas.

Seeberger et al. (7) studied 7 cases of MALT lymphoma and determined CD95 expression quantitatively by flow cytometry. Three of the patients presented low levels and 4 very low levels of CD95. In spite of the different methods used, heterogeneous CD95

Table 1. Cases diagnosed as chronic gastritis and mucosa-associated lymphoid tissue (MALT) lymphomas with the respective scores for reaction with anti-CD95/APO1.

\begin{tabular}{lll}
\multirow{2}{*}{ Score } & \multicolumn{2}{c}{ Number of cases } \\
\cline { 2 - 3 } & Chronic gastritis & MALT lymphomas \\
\hline 0 & 0 & $1(6.6 \%)$ \\
$1+$ & $1(6.6 \%)$ & $4(26.6 \%)$ \\
$2+$ & $5(33.3 \%)$ & $4(26.6 \%)$ \\
$3+$ & 0 & $3(20 \%)$ \\
$4+$ & $9(60 \%)$ & $3(20 \%)$ \\
\hline
\end{tabular}

See Methods for scoring. The difference between the two groups ( $N=15$ each) was statistically significant $(P=0.03$, Mann-Whitney test). immunoexpression in MALT lymphomas was a finding in common with our results. On the other hand, these investigators suggested that there might be different degrees of sensitivity to CD95-mediated apoptosis among patients and that such sensitivity might not be related to the level of CD95 expression. They showed that cases of MALT lymphomas with the lowest levels of CD95 expression were the most sensitive to in vitro apoptosis (7).

As MALT lymphomas do express CD95, the mechanism of oncogenesis among them could be acquisition of resistance to CD95mediated apoptosis either by mutation or inactivation of CD95 (7). It has been recently shown that $5.6 \%$ of primary gastric MALT lymphomas and $14.3 \%$ primary gastric large B-cell lymphomas present Fas (CD95) mutations which might contribute to the pathogenesis of gastric lymphomas by inducing involved lymphocytes to resistance to apoptosis (9). The increased resistance to apoptosis may also be due to the elevated expression of $b c l-2$, especially in lymphomas of low histological grade (5). In addition, other mechanisms of control of apoptosis other than the CD95 pathway might be involved in the genesis of lymphomas.

To the best of our knowledge, no other study has addressed the in situ immunoexpression of CD95 in H. pylori-related chronic gastritis. Nine of our cases $(60 \%)$ had strong and diffuse positivity (score 4+), and in no instance were lymphocytes totally negative. Higher levels of CD95 expression in reactive lymphocytes in comparison to MALT lymphomas were also detected in a quantitative study using flow cytometry (7).

As we did not perform double staining, it cannot be ascertained which lymphoid subset presented CD95. However, it is highly probable that both $\mathrm{B}$ - and T-lymphocytes expressed this protein since it has been shown that stimulation of B-lymphocytes by activated T-cells elevated their levels of CD95 (7). Our results also support the previous 
observation of elevation of CD95 in lymphoid infiltrates and adjacent epithelial cells (4). It has been suggested that damage to epithelial cells in autoimmune or $H$. pylorirelated gastritis might occur through CD95mediated apoptosis $(10,11)$.

Overlapping of immunostaining patterns among our cases of chronic gastritis and lymphomas indicates that the use of CD95 for differential diagnosis is not reliable, in spite of significantly lower expression in lymphomas. However, the difference in CD95 positivity between both groups supports the hypothesis that down-regulation of this apoptosis-related protein might play a role in cell survival during MALT lymphomagenesis.

\section{Acknowledgments}

The authors wish to thank Dr. Luciano de Souza Queiroz for review of the manuscript.

\section{References}

1. Miyawaki T, Uehara T, Nibu R, Tsuji T, Yachie A, Yonehara S \& Taniguchi N (1992). Differential expression of apoptosis-related Fas antigen on lymphocyte subpopulation in human peripheral blood. Journal of Immunology, 149: 3753-3758.

2. Lagresle C, Bella C, Daniel PT, Krammer PH \& Defrance T (1995). Regulation of germinal center $B$ cell differentiation. Role of the human APO-1/Fas (CD95) molecule. Journal of Immunology, 154: 5746-5756.

3. Möller P, Henne C, Leithäuser F, Eichelmann A, Schmidt A, Brüderlein S, Dhein J \& Krammer PH (1993). Coregulation of the APO-1 antigen with intercellular adhesion molecule-1 (CD54) in tonsillar B cells and coordinate expression in follicular center B cells and in follicle center and mediastinal B-cell lymphomas. Blood, 81: 2067-2075.

4. Leithäuser F, Dhein J, Mechtersheimer G, Koretz K, Brüderlein S, Henne C, Schmidt A, Debatin KM, Krammer PH \& Möller P (1993). Constitutive and induced expression of APO-1, a new member of the nerve growth factor/tumor necrosis factor receptor superfamily, in normal and neoplastic cells. Laboratory Investigation, 69: 415429.

5. Nguyen P, Harris NL, Ritz J \& Robertson MJ (1996). Expression of CD95 antigen and bcl-2 protein in non-Hodgkin lymphomas and
Hodgkin disease. American Journal of Pathology, 148: 847-853.

6. Plumas J, Jacob MC, Chaperot L, Molens JP, Sotto JJ \& Bensa JC (1998). Tumor B cells from non-Hodgkin lymphoma are resistant to CD95 (Fas/Apo-1)-mediated apoptosis. Blood, 91: 2875-2885.

7. Seeberger H, Starostik P, Schwarz S, Knörr C, Kalla J, Ott G, MüllerHermelink HK \& Greiner A (2001). Loss of Fas (CD95/APO-1) regulatory function is an important step in early MALT-type lymphoma development. Laboratory Investigation, 81: 977-986.

8. Isaacson PG (1994). Gastrointestinal lymphoma. Human Pathology, 25: 1020-1029.

9. Wohlfart S, Sebinger D, Gruber P et al. (2004). FAS (CD95) mutations are rare in gastric MALT Iymphoma but occur more frequently in primary gastric diffuse large B-cell lymphoma. American Journal of Pathology, 164: 1081-1089.

10. Wang J, Fan X, Lindholm C, Bennett M, O'Connoll J, Shanahan F, Brooks EG, Reyes VE \& Ernst PB (2000). Helicobacter pylori modulates lymphoepithelial cell interactions leading to epithelial cell damage through Fas/Fas ligand interactions. Infection and Immunity, 68: 4303-4311.

11. Marshall AC, Alderuccio F \& Toh BH (2002). Fas/CD95 is required for gastric mucosal damage in autoimmune gastritis. Gastroenterology, 123: 780-789 